\title{
O consumo em tiras cômicas no ensino de ELE: leitura e letramento crítico
}

\author{
Valdiney da Costa Lobo \\ Universidade Federal do Rio de Janeiro
}

\begin{abstract}
Resumo
Este artigo apresenta uma proposta de atividades de leitura na aula de espanhol a partir de uma tira cômica, a fim de problematizar a questão social do consumo. Alinho-me a uma perspectiva de compreensão leitora ancorada na construção de sentidos (KLEIMAN, 2007; TILIO, 2012; BRASIL, 1998). A pesquisa também foi realizada com base nos conceitos de ideologia e hegemonia (FAIRCLOUGH, 2001), pois eles contribuem para uma proposta de letramento crítico (BRASIL, 2006). Dessa forma, além da realização de atividades de compreensão textual, também se torna possível desenvolver a consciência crítica a partir de questionamentos sobre o consumo adolescente contemporâneo.
\end{abstract}

Palavras-chave: letramento crítico; tira cômica; espanhol.

\begin{abstract}
This paper presents a proposal of reading activities in Spanish class from a comic strip in order to problematize the social question of consumerism. I align myself with the perspective of reading comprehension anchored in the construction of meaning (KLEIMAN, 2007; TILIO, 2012; BRASIL, 1998). The research was also based on the concepts of ideology and hegemony (FAIRCLOUGH, 2001) since they contribute to a proposal of critical literacy (BRASIL, 2006). Thus, in addition to performing activities of reading comprehension, it also becomes possible to develop a critical awareness from questions about contemporary teen consumerism.
\end{abstract} Keywords: critical literacy; comic strip; Spanish.

\section{INTRODUÇÃO}

O presente artigo possui o seu foco na formação cidadã dos alunos (BRASIL, 1998a) a partir de uma proposta de leitura de uma tira sobre a questão social do consumo adolescente na sociedade contemporânea. Este fato permite aos discentes a compreensão das finalidades sociais das tiras cômicas com base em um olhar crítico e reflexivo, nos âmbitos escolar e social, acerca do consumo adolescente. A proposta baseia-se na perspectiva da leitura crítica e do letramento crítico (BRASIL, 2006) e divide-se em três 
etapas: pré-leitura, leitura e pós-leitura.

$\mathrm{Na}$ fase de leitura, priorizam-se as atividades de compreensão detalhada e global (leitura crítica) ancoradas na tira. Dessa forma, a partir da elaboração de atividades de leitura crítica (BRASIL, 2006), os alunos podem ter a possibilidade de desenvolver o entendimento geral e específico por meio de inferências e levantamento de hipóteses. Na pós-leitura privilegia-se um posicionamento crítico a partir de questionamentos sobre o consumo adolescente contemporâneo (letramento crítico). A leitura nesta perspectiva apresenta a possibilidade do desenvolvimento da consciência crítica (BRASIL, 2006), promovendo problematizações sobre os perfis de adolescentes consumidores contemporâneos. Esta vertente possibilita a discussão, em sala de aula, sobre os discursos que são legitimados de forma hegemônica acerca do consumo por meio de construções ideológicas (FAIRCLOUGH, 2001), assim como os perfis de adolescentes representados/excluídos das tiras.

\section{A QUESTÃo SOCIAL DO CONSUMO NA AULA DE ELE}

O foco deste artigo é apresentar uma proposta de atividade de leitura em língua estrangeira sob a vertente da significância social, apresentando uma possibilidade ainda mais ampla a partir da proposta presente no documento introdutório dos Parâmetros Curriculares, doravante, PCN-IN (BRASIL, 1998a). De acordo com este documento, os temas transversais relacionam-se aos problemas sociais urgentes; não somente de alcance nacional, mas também universal. Estes temas são: Ética, Meio Ambiente, Saúde, Pluralidade Cultural, Orientação Sexual e Trabalho \& Consumo. Para Moita Lopes (2003), eles abrangem problemáticas relacionadas à vida social na contemporaneidade, possibilitando, em sala de aula, um trabalho de reflexão com os estudantes sobre questionamentos pertinentes às sociedades contemporâneas.

É nesse contexto que este artigo propõe a abordagem do tema transversal Trabalho e Consumo na sala de aula de língua espanhola. De forma mais específica, essa pesquisa enfoca na questão social do "consumo". Apesar de a temática ser construída sob a perspectiva do consumo e do trabalho, apenas o primeiro será fundamental para o objetivo desse trabalho. 
A discussão desse tema no âmbito escolar é pertinente a uma turma de adolescentes, porque eles são constantemente afetados pelas práticas de consumo existentes na sociedade. De fato, muitas das interações sociais de jovens de classe média na contemporaneidade são perpassadas por diálogos acerca de produtos tecnológicos, tênis e roupas de marca, assim como a importância do significado social obtido por quem possui estas mercadorias.

Torna-se importante ressaltar que nem todos os adolescentes brasileiros possuem acesso aos produtos divulgados constantemente nas diversas mídias. O PCN-TC, (BRASIL, 1998c) ressalta a diversidade e a desigualdade existentes nas escolas do Brasil. Em algumas delas, os alunos podem escolher entre diversos materiais didáticos para serem usados ao longo do ano; enquanto em outras, há grande falta desses objetos, inclusive dos básicos.

A sociedade constrói uma mensagem de que todos os cidadãos têm direitos iguais, até mesmo a liberdade para escolher o que devem consumir. Essa afirmação mascara a realidade social do Brasil, porque essa escolha não se preocupa com o acesso diferenciado aos bens de consumo existente entre as diversas classes sociais. Segundo os PCN-TC

um direito básico do cidadão é ter acesso ao mercado de consumo, aos produtos ou serviços que são oferecidos. Embora, aparentemente, exista o livre acesso de todos aos bens de consumo e serviços, reconhece-se a existência de "bolsões" de consumo diferenciados: se em alguns o consumo de bens é praticamente ilimitado, em outros existe a impossibilidade de acesso aos bens de consumo e serviços considerados vitais. Trata-se, portanto, de reivindicar o acesso ao consumo como um direito fundamental de cidadania (BRASIL, 1998c, p. 16).

Sob a ótica deste documento oficial, observa-se que nem todos os cidadãos possuem igualdade de direitos em relação à prática do consumo na sociedade. Ressaltar esta dinâmica social na aula de língua espanhola é importante, pois aproxima o aluno de discussões socioeconômicas brasileiras. Assim, negocia-se o objetivo de "se pensar a língua estrangeira de um modo que reflita os interesses do Brasil" (MOITA LOPES, 1996, p. 42).

Defendo o debate sobre o consumo na aula de língua estrangeira, porque vivemos em um meio social orientado para esta prática. Os alunos são adolescentes e jovens imersos em um meio social que os convoca constantemente a consumir. Não se pode negar que "a vivência juvenil é hoje fortemente marcada pela importância dada ao lazer e 
ao consumo". (BRASIL, 1998c, p. 48). Entretanto, apesar de todos serem convocados, muitos não têm condições financeiras de participar deste mercado consumidor adolescente imposto pela mídia global.

No bojo desse cenário, uma aula de espanhol orientada ao debate da questão social do consumo, mais especificamente das identidades dos adolescentes consumidores contemporâneos, coloca em voga a dimensão política do ensino de línguas estrangeiras na escola. Anteriormente, mencionei que docentes e discentes precisam ancorar-se numa proposta de aula politizada. Contudo, para haver este tipo de posicionamento, a própria finalidade do ensino de línguas estrangeiras na escola deve ser rediscutida com os alunos em sala de aula.

Alinho-me a favor de questionamentos que possibilitem um olhar emancipatório e crítico, vinculados a uma proposta de mudança social. Esta mudança pode começar por meio da ressignificação da prática pedagógica. Em consonância com o exposto, “entendo que o ensino de língua estrangeira deve estar atento ao contexto político em que o mesmo se dá, tanto quanto aos aspectos estritamente linguísticos" (RAJAGOPALAN, 2006. p. 20). Em se tratando do foco desta comunicação, a habilidade de cunho linguístico problematizada neste artigo é a compreensão leitora. Compreendo a leitura como uma construção de sentidos (BRASIL, 1998b). Uma proposta pedagógica promovida por meio desse prisma abre espaço para que os estudantes se redefinam no papel de adolescentes consumidores por meio da negociação de sentidos com as identidades juvenis perpassadas pela prática do consumo e construídas pelas tiras analisadas.

\section{A LEITURA DE TIRAS COMO CONSTRUÇÃO DE SENTIDOS: LEITURA CRÍTICA E LETRAMENTO CRÍTICO}

Alinho-me ao enfoque da questão social do consumo na aula de língua espanhola a partir de uma proposta de compreensão leitora de quadrinhos. As atividades de leitura que defendo nesta investigação estão ancoradas em práticas discursivas, na produção de sentidos e na construção de significados (CORACINI, 2002; KLEIMAN, 2007; TILIO, 2012,) e segue a perspectiva sugerida pelos PCN-LE (BRASIL, 1998b). Para Coracini (2002), nesta prática de leitura, autor e leitor são indivíduos socio-históricos, produtores de sentidos, perpassados por posicionamentos discursivos que são negociados e 
construídos nos diversos contextos sociais.

De acordo com os PCN-LE (BRASIL, 1998b), é relevante que os alunos desenvolvam três tipos de conhecimentos com a mediação do professor: o de mundo, o sistêmico e o textual. O primeiro relaciona-se à bagagem e às experiências de vida que os indivíduos utilizam para negociar a compreensão dos gêneros discursivos. $\mathrm{O}$ segundo relaciona-se ao próprio sistema da língua, ao nível de organização linguística, e aborda a forma como aspectos léxicos, semânticos, morfológicos e sintáticos são construídos pelos discursos. O último articula-se ao conhecimento que os indivíduos possuem para organizar informações em gêneros discursivos, sejam eles orais ou escritos.

A linguagem verbal da tira em quadrinhos selecionada para esse artigo está em consonância com o período atual da contemporaneidade e o local de sua produção e circulação é a sociedade argentina. Por isso, a prática de leitura dos conhecimentos sistêmicos permite ao aluno compreender como as posições de adolescentes contemporâneos são culturalmente construídas no Brasil e na Argentina. As representações lexicais dos quadrinhos podem construir juvenis consumidores descontrolados ou conscientes, e isso se manifesta por meio da organização do texto.

Sinalizo que as atividades de leitura foram construídas em consonância com a perspectiva apresentada pelos PCN-LE (BRASIL, 1998b): pré-leitura, leitura e pósleitura. Por fim, ressalto que durante a etapa de leitura prevalecem as questões orientadas à leitura crítica, pois os alunos se apropriam do uso de estratégias como as inferências e as compreensões global e específica. Em se tratando da pós-leitura, há uma maior presença de atividades que promovem o letramento crítico, pois, nesta etapa os discentes poderão construir discursos ancorando-se nas relações entre as representações sociodiscursivas das tiras e a realidade social em que estão inseridos. A construção deste espaço de discussão é importante para fomentar uma prática discursiva orientada à elaboração de discursos contra-hegemônicos, críticos e transformadores (FAIRCLOUGH, 2001).

Com o objetivo de promover as reflexões supracitadas em sala de aula, torna-se importante retomar as vertentes de leitura crítica e letramento crítico que perpassaram as construções das atividades de compreensão leitora e segue a perspectiva sugerida pelos PCN-LE (BRASIL, 1998b). Nas duas propostas de leitura, autor e leitor são indivíduos 
socio-históricos, produtores de sentidos, perpassados por posicionamentos discursivos que são negociados e construídos nos diversos contextos sociais. Na sequência, demonstro a tabela presente nas OCEM (BRASIL, 2006), que estabelece a diferença entre a leitura crítica e o letramento crítico.

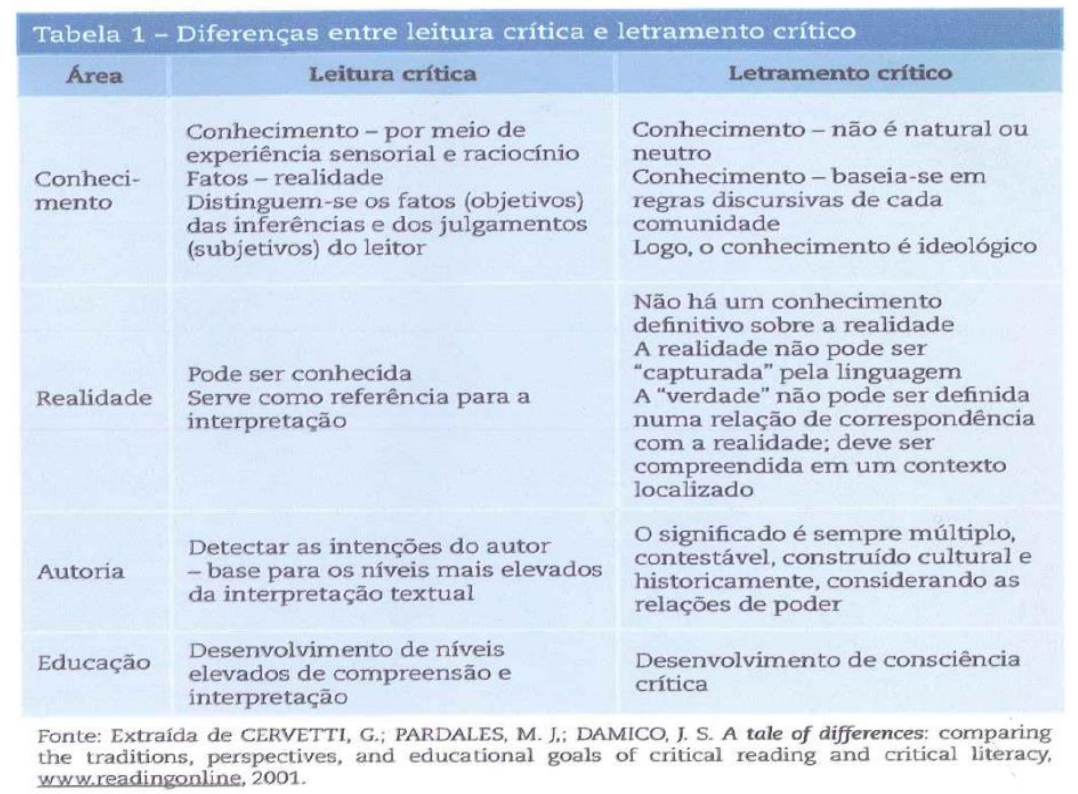

Fonte:http://portal.mec.gov.br/seb/arquivos/pdf/book_volume_01_internet.pdf

Conforme pode ser observado na tabela acima, em se tratando da leitura crítica, o objetivo é o desenvolvimento de níveis de compreensão leitora, de acordo com a realidade apresentada na tira. Para isso, os discentes poderão usar estratégias como a inferência e o levantamento de hipóteses. Em relação ao letramento crítico, ressalta-se que ele se relaciona com as representações sociais, analisando quem ganha e quem perde nas relações socio-históricas (BRASIL, 2006). O importante é compreender os contextos social e histórico, ambos perpassados por relações de poder. Nesse sentido, torna-se importante o reconhecimento das representações sociais de adolescentes consumidores, ideologicamente legitimadas pela tira. Esta perspectiva possibilita a construção de uma consciência crítica por parte dos alunos, a fim de que problematizem quais perfis de adolescentes consumidores estão representados de forma hegemônica na tira e por que outros perfis são excluídos. Na sequência, apresento as atividades elaboradas com a finalidade de realizar uma proposta de leitura crítica e de letramento crítico. 


\section{ATIVIDADES COM A TIRA}

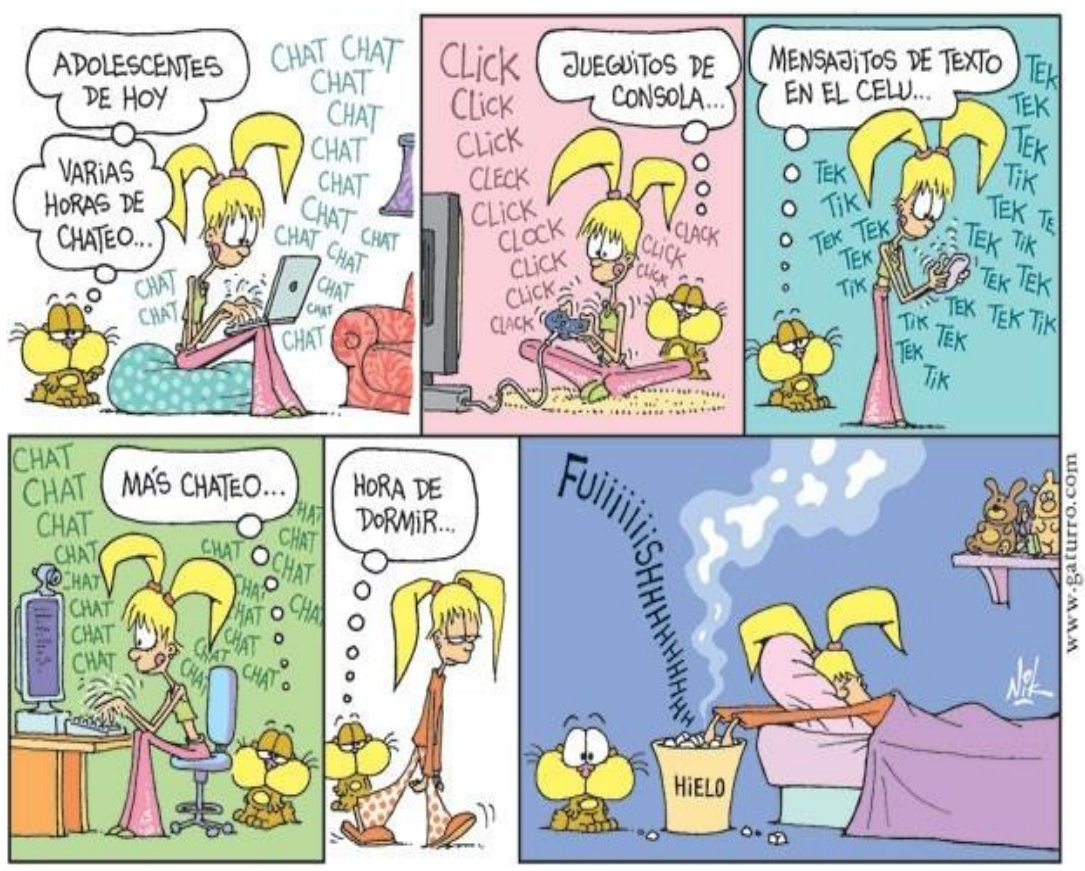

Fonte: www.gaturro.com

Para esta tira, elaborei cinco perguntas. A letra "a" é de pré-leitura, as questões "b" e "c" são de leitura. A partir delas são necessárias inferências dos interlocutores na negociação dos sentidos das linguagens verbal e não verbal materializadas na tira. As questões "d" e "e" são de pós-leitura e problematizam respectivamente o consumo excessivo de novas tecnologias por juvenis contemporâneos, assim como indaga a respeito dos adolescentes que não possuem acesso a estas mídias.

\section{Prelectura (Pré-leitura)}

a) ¿Te gusta más la computadora, el celular o el videojuego? ¿Por qué?

Você gosta mais de usar o computador, o celular ou o videogame? Por quê? 
b) ¿De qué manera se representa la adolescente del cómic y cómo las imágenes y las onomatopeyas contribuyen para eso?

De que maneira a adolescente é representada na tira e como as imagens e as onomatopeias contribuem para isso

c) Para ti, ¿qué significa la palabra "chateo"?

Para você, o que significa a palavra "chateo"?

Poslectura (Pós-leitura)

d) ¿Todos los adolescentes son adictos a las nuevas tecnologías, igual que la chica de la tira? Justifícalo.

Todos os adolescentes são viciados nas novas tecnologias como a adolescente da tira? Justifique.

e) ¿La adolescente del cómic, con computadora, celular y videojuego en su casa, representa el perfil de todos los adolescentes brasileños? Justifícalo.

A adolescente da tira, com computador, celular e videogame em sua casa, representa o perfil de todos os adolescentes brasileiros? Justifique.

A primeira pergunta possui o objetivo de mapear qual aparelho eletrônico os alunos mais gostam de usar: se é o celular, o computador ou o videogame. Na tira, Luz utiliza intensamente todos eles, entretanto, há uma predominância pelo uso dos computadores, pois ela opta por eles em dois momentos. Dessa forma, também busco averiguar em que medida os participantes se apropriam mais de "desktops" ou "notebooks" em detrimento das outras tecnologias.

A questão "b", "De que maneira a adolescente é representada na tira e como as imagens e as onomatopeias contribuem para isso?", tem a finalidade de promover indagações acerca do conhecimento de mundo dos estudantes, ancorando-se no atual momento socio-histórico contemporâneo perpassado pela globalização. A compreensão leitora dos estudantes sobre o perfil de adolescente representado na tira deve ser construída por meio das linguagens verbal e não verbal. Por isso, a existência de palavras como "videojuego" e "celu..", referindo-se ao celular, permitem uma analogia entre as línguas espanhola e portuguesa, auxiliando o entendimento das imagens materializadas na tira. 
Em relação ao item “c”, "Para você, o que significa a palavra chateo?”, o importante é que os alunos realizem inferências sociais e linguísticas na perspectiva de negociarem os significados em espanhol do substantivo "chateo". Parece-me importante ressaltar que no português do Brasil não há uma palavra específica para diálogos pelo computador, já que uma "conversa" pode ser tanto real quanto virtual. Por outro lado, usamos a palavra "chat" para se referir a um local de "bate-papo" virtual, mas não nomeamos a ação de estar naquele espaço da virtualidade. Além disso, abre-se a oportunidade para a compreensão de que o verbo "to chat" do inglês originou "chatear" e o substantivo chateo em espanhol, ambos de uso frequente em Buenos Aires.

A pergunta de pós-leitura "d", "Todos os adolescentes são viciados em aparelhos eletrônicos conforme a adolescente da tira? Justifique", direciona o olhar para um processo de formação cidadã do aluno porque propõe uma atividade de relação dialógicodiscursiva orientada a averiguar em que medida os estudantes se identificam com o perfil homogêneo de adolescente adicto às novas tecnologias, conforme o padrão presente na tira. Este item também negocia uma justificativa com os estudantes. A indagação proposta possibilita a manifestação de uma pluralidade de sentidos discursivos dos participantes a fim de construir um espaço onde diversas vozes sejam ouvidas, valorizando, assim, a heterogeneidade da sala de aula.

O item "e", "A adolescente presente na tira, com computador, celular e videogame em sua casa, representa o perfil de todos os adolescentes do Brasil? Justifique", enfoca o conhecimento de mundo dos alunos acerca do acesso de juvenis de muitas partes do planeta às novas tecnologias em suas casas. Vale a pena ressaltar que a pergunta está direcionada ao fato de os adolescentes possuírem acesso em suas residências, até porque há uma quantidade razoável de lan houses nas periferias dos centros urbanos, nas quais se pode pagar por hora de conexão.

Entendo que apesar de o acesso tecnológico ter crescido no Brasil nos últimos anos, devido também à ascensão das classes "e" e "d", ainda existem muitos adolescentes desconectados da rede mundial, não somente em nosso país, mas na periferia do mundo, espaço em que a globalização cumpre o seu papel neoliberal de aumentar as diferenças sociais e naturalizar a pobreza. Essa pergunta contribui para uma reflexão acerca dos adolescentes excluídos do acesso a esses bens de consumo, assim como para a 
problematização das razões dessa exclusão.

\section{CONSIDERAÇÕES FINAIS}

As propostas de compreensão leitora perpassadas pelas perspectivas da leitura crítica e do letramento crítico possibilitam aos alunos, respectivamente, o desenvolvimento de níveis de compreensão do texto e de uma consciência crítica. Portanto, as perguntas baseadas na tira cômica apresentada neste artigo buscaram direcionar um olhar para estes dois tipos de leitura, que não são excludentes, pelo contrário, são complementares.

Busquei problematizar a naturalização da diferença socioeconômica dos diversos perfis de adolescentes existentes no mundo. O foco está na abertura do espaço da sala de aula para a compreensão dos alunos de que esta diferença foi/é construída de forma socio-histórica por determinados grupos privilegiados economicamente. Dessa forma, os discentes podem observar que a sociedade global, por meio de seus veículos de comunicação midiáticos, possui o objetivo de divulgar um padrão hegemônico de consumo, assim como naturalizar a condição de pobreza humana, na qual estão inseridos os indivíduos de classes socioeconômicas mais desfavoráveis. Estas pessoas não são convocadas pelo mercado consumidor, sendo, portanto, os excluídos sociais. Além disso, as perguntas propostas buscaram contribuir para a (re)definição dos adolescentes como consumidores, a fim de que consumam de maneira mais equilibrada, de acordo com as suas reais necessidades.

Nesse cenário, a sala de aula de língua espanhola constitui-se num espaço privilegiado para que professores e alunos sejam capazes de "pensar alternativas para a vida social" (MOITA LOPES, 2006, p. 22), promovendo diálogos sobre o consumo adolescente na contemporaneidade. Por isso, torna-se importante valorizar e respeitar as diferentes opiniões dos estudantes, pois a multiplicidade de discursos contribui para a existência de uma sala de aula heterogênea. 


\section{REFERÊNCIAS}

BRASIL. Orientações Curriculares para o Ensino Médio. Vol 1. Brasília: Ministério da Educação,Secretaria de Educação Básica, 2006.

BRASIL. Secretaria de Educação Fundamental. Parâmetros curriculares nacionais: terceiro e quarto ciclos do ensino fundamental: apresentação dos temas transversais. Brasília: MEC/SEF, 1998a.

BRASIL. Secretaria de Educação Fundamental. Parâmetros curriculares nacionais: terceiro e quarto ciclos do ensino fundamental: língua estrangeira. Brasília: MEC/SEF, 1998b.

BRASIL. Secretaria de Educação Fundamental. Parâmetros curriculares nacionais: terceiro e quarto ciclos do ensino fundamental: tema transversal "Trabalho e Consumo". Brasília: MEC/SEF, 1998c, p. 337-406.

CORACINI, M. J. (Org.). O jogo discursivo na aula de leitura. 2ed. Campinas: Pontes, 2002.

FAIRCLOUGH, Norman. Discurso e Mudança Social. Brasília: Editora Universidade de Brasília, 2001.

KLEIMAN, A. Formando leitores críticos. In: MARI,H; WALTY,I; FONSECA, M. (Orgs.) Ensaios sobre leitura 2. Belo Horizonte: Editora PUC, 2007, p. 99-123.

MOITA LOPES, L. P. A nova ordem mundial, os Parâmetros Curriculares Nacionais e o ensino de inglês no Brasil: a base intelectual para uma ação política. In: BARBARA, L.;ROCHA, R. C. G. (Orgs.) Reflexão e ações no ensino-aprendizagem de línguas. Campinas: Mercado de Letras, 2003.

MOITA LOPES, L. P. Linguística Aplicada e Vida Contemporânea: problematização dos construtos que têm orientado a pesquisa. In: MOITA LOPES. L. P. (Org.) Por uma linguística aplicada indisciplinar. São Paulo: Parábola Editorial. 2006, p. 85-108.

MOITA LOPES, L. P. Oficina de Linguística Aplicada. Campinas: Mercado de Letras, 1996.

RAJAGOPALAN, K. O ensino de línguas estrangeiras como uma questão política. In: MOTA, K; SCHEYERL (Orgs.) Espaços Linguísticos: resistências e expansões. Salvador: EDUFBA, 2006, p. 15-23.

TILIO, R. C. Enfoque em leitura no ensino de inglês: PCN e letramento crítico. In: III Congresso 
Internacional da ABRAPUI, 2012, Florianópolis. Programação e caderno de resumos, 2012, p. 232-233.

\section{O AUTOR}

Valdiney da Costa Lobo, doutorando, UFRJ

E-mail: valdineylobo@gmail.com 